\title{
Motivational properties of the CS in conditioned suppression
}

The duration of complete suppression of consummatory drinking by a single presentation of a previously conditioned fear-eliciting CS was greater when the CS was present throughout the suppression interval than when the CS was presented for the duration used on each conditioning trial. Thus, presence of the CS seems to have motivational properties that are distinct from those of CS onset and time after CS onset.

It is commonly assumed that the presence of a CS that has been paired with shock has motivational properties, since such CSs suppress appetitively motivated responses (Estes \& Skinner, 1941) and they may be aversive (Miller, 1948). Several aspects of the behavior observed in conditioned suppression experiments, however, suggest that this assumption could be questioned. The onset of the CStypically leads to complete suppression of appetitive responses after a few conditioning trials, and the suppression ends immediately after receipt of a painful shock after conditioning is well established (see e.g., Leaf \& Muller, 1964). These observations suggest that stimulus changes may produce essentially all-or-none changes in response levels, and that presence or absence of the CS, per se, may be of little importance. This latter suggestion is further supported by the results of studies of conditioned suppression with trace CSs (Kamin, 1961), in which partial suppression seemed to increase in steps with the successivestimulus changes throughout the trace interval.

The present experiment was an explicit test of whether the presence of a CS does, in fact, have motivational properties.

Method

Subjects. The Ss were $40,200-250 \mathrm{gm}$ female albino rats (Holtzman Co., Madison, Wisc.), maintained on ad libitum food and water prior to experimentation.

Apparatus. The apparatus was a small behavior chamber that has been described elsewhere (Leaf \& Muller, 1965). It had a grid floor through which painful shocks could be delivered, a dipper which could be filled with water automatically, and a loudspeaker to generate tone CSs.

Procedure. There were two experimental sessions for each S. A conditioning session during which a CS was paired with shock was followed, after $48 \mathrm{hr}$. of water deprivation, by a test session during which consummatory drinking of tap water was suppressed by a single CS presentation.

All Ss were treated identically during the conditioning session. They were given 10 conditioning trials with a 4-sec. CS (a 500-cps, 80-db tone), a 1-sec.CS-US interval, a 3-sec. 0.75 ma US, and a 1-min. intertrial interval.

During the test session, each $S$ was placed in the chamber and allowed to lick from the dipper, which was refilled each $30-\mathrm{sec}$. Each lick was counted by means of a drinkometer (Grason-Stadler Co., West Concord, Mass.), and the CS was turned on when the 100th lick was recorded. The CS was terminated at one of two times, depending upon which of two experimental conditions had been randomly assigned to each S. For one group of 20 Ss the CS was terminated by the 10th lick after its onset, and for the other it was terminated after 4 sec., as it had been on each trial during the conditioning session. The duration of suppression preceding recovery of drinking was measured by recording the time of the 10th lick after CS onset for each S (Leaf \& Leaf, 1966).

\section{Results}

The mean suppression duration of Ss that had a 4-sec. test CS was 1.75 min., but that of Ss for which the CS remained present until recovery of drinking had occurred was $4.14 \mathrm{~min}$. This difference was significant $(\mathrm{t}=2.3, \mathrm{df}=38, \mathrm{p}<.05)$.

\section{Discussion}

The presence of a CS does maintain conditioned suppression, and it would seem that the common assumption that the presence of the CS has motivational properties is correct, at least for the delayed conditioned CSs used here. Whether the observed group differences were due to active suppression by the maintained CS, or to release of suppression by restoration of the (relatively safe) intertrial stimuli, in the 4-sec. test CS condition, is irrelevant for this conclusion. Either cause of the results would imply a role of the presence of the CS in suppression maintenance.

\section{References}

Estes, W. K., \& Skinner, B. F. Some Quantitative properties of anxiety. J. exp. Psychol., 1941, 29, 390-400.

Kamin, L. J. Trace conditioning of the conditioned emotional response. J. comp. physiol. Psychol., 1961, 54, 149-153.

Leaf, R. C., \& Leaf, S. R. P. Recovery time as a measure of degree of conditioned suppression. Psychol. Rep., 1966, 18, 265-266.

Leaf, R. C., \& Muller, S. A. Effect of CER on DRL responding. J. exp. Anal. Behav., 1964, 7, 405-407.

Leaf, R. C., \& Muller, S. A. Simple method for CER conditioning and measurement. Psychol. Rep., 1965, 17, 211-215.

Miller, N. E. Studies of fear as an acquirable drive. I. Fear as motivation and fear-reduction as reinforcement in the learning of new responses. J. exp. Psychol., 1948, 38, 89-101. 